\title{
Francisco Suárez (1548-1617): Escolástica y mundo moderno
}

Francisco Suárez (1548-1617): Scholasticism and modern world

Víctor Sanz SANTACRUZ

Universidad de Navarra

Departamento de Filosofía

Facultad de Filosofía y Letras

31009 Pamplona (España)

vsanz@unav.es
Abstract: This special issue aims to contribute to the celebration of the fourth centenary of Francisco Suárez's death (1548-1617). Its intention is to bring up to date this Spanish Jesuit's thought in all of its multidisciplinary variety, ranging from metaphysics, philosophical psychology, political philosophy, law and economics, to the theory of action. In carrying out this task, we have tried to address the main ideas of this complex and contorversial author, who bridges medieval and modern ways of thinking, from the contemporary perspectives of the above mentioned disciplines.

Keywords: Francisco Suárez, Spanish thought.

\author{
$M^{a}$ IDOYA ZORROZA \\ Universidad de Navarra \\ Departamento de Filosofía \\ Facultad de Filosofía y Letras \\ 31009 Pamplona (España) \\ izorroza@unav.es
}

Resumen: El presente volumen monográfico quiere aportar a la celebración del cuarto centenario del fallecimiento de Francisco Suárez (1548-1617), una reactualización del pensamiento de este jesuita español en su carácter multidisciplinar: desde la metafísica, la psicología filosófica, la filosofía política, el derecho y la economía a la teoría de la acción. Con ello se busca abordar desde el panorama contemporáneo de estas disciplinas las tesis de este autor complejo y controvertido, puente y gozne entre el pensamiento medieval y el moderno.

Palabras clave: Francisco Suárez, pensamiento español. 
a celebración en este año 2017 del cuarto centenario del fallecimiento de Francisco Suárez, uno de los pensadores españoles de más trascendencia internacional, era la ocasión de recordar y reactualizar las propuestas intelectuales de este jesuita granadino desde un acercamiento intelectual multidisciplinar (como sus escritos) y una serena valoración de este autor cuyo pensamiento no ha estado exento de cierto debate y perplejidad.

Con esta intención, en el curso 2013-14, el entonces Director de la Línea Especial, el Dr. Ángel Luis González, tristemente fallecido hace ya un año, quiso que esta onomástica fuera la ocasión de reactualizar la figura de este filósofo y teólogo haciendo confluir, en ese horizonte del 2017, la investigación de los distintos subproyectos de la Línea Especial y el estudio de sus investigadores ${ }^{1}$. Era el momento de destacar su aportación intelectual, y hacerlo subrayando al mismo tiempo su vinculación con lo mejor del pensamiento español. De esta manera nos sumábamos a la labor que desde otros muchos países se estaba haciendo de dialogar los distintos temas filosóficos y teológicos con sus propuestas intelectuales, revisando sus afirmaciones para que dieran de sí en el panorama intelectual contemporáneo ${ }^{2}$.

1. Entre las actividades previstas para el año 2017 estaban contempladas las siguientes: las LIII Reuniones Filosóficas, celebradas en Pamplona en abril de 2017; el IV Encuentro Internacional de Historia del Pensamiento Entre el Renacimiento y la Modernidad: Francisco Suárez (1548-1617), celebrado en Salamanca en marzo de 2017; y además de las publicaciones vinculadas a éstas, tres monográficos de revistas de prestigio: este volumen de Anuario Filosófico, un monográfico en Scientia et Fides, y otro monográfico en Cauriensia. Además de una exposición virtual y presencial del Fondo Antiguo de la Universidad de Navarra sobre Francisco Suárez. Gracias al trabajo, interés y a la colaboración de muchos de los investigadores de la Línea, junto a otros colaboradores ajenos a la Universidad, se han podido llevar a cabo estas actividades previstas.

2. Muestra del interés por Francisco Suárez es la reciente publicación de tres obras colectivas en las más prestigiosas editoriales a nivel internacional: B. HiLL, H. Lagerlund (eds.), The Philosophy of Francisco Suárez (Oxford University Press, Oxford, 2012); D. SCHWARTz (ed.), Interpreting Suárez: Critical Essays (Cambridge University Press, Cambridge, 2013); M. SGarbi (ed.), Francisco Suárez and his Legacy: The Impact of Suárezian Metaphysics and Epistemology on Modern Philosophy (Vita e Pensiero, Milano, 2010); V. Salas, R. L. Fastiggi (eds.), A Companion to Francisco Suárez (Brill, Leiden, 2015), por no mencionar la obra de J. P. Coujou, Bibliografía suareciana (Servicio de Publicaciones de la Universidad de Navarra, Pamplona, 2010; reimpr. corregida, 2015). 
La preparación del centenario por parte de los investigadores de la Línea Especial de Pensamiento clásico español se concretaría en una serie de actividades ${ }^{3}$ entre las que están incluidas ya en el mismo año del centenario la organización de las LIII Reuniones Filosóficas en la Universidad de Navarra ${ }^{4}$ y el presente monográfico de Anuario Filosófico. Con todas ellas se ha pretendido abordar las propuestas intelectuales de Suárez desde distintas disciplinas, invitando a colaborar a especialistas e investigadores de su obra para establecer un fecundo diálogo filosófico, revisitando las obras de Suárez con una mirada puesta en la problemática contemporánea.

Y es que Francisco Suárez es, todavía hoy, un autor complejo y controvertido. El hecho de que contemos con una obra tan extensa y no siempre bien conocida es un motivo para su complejidad, puesto que es difícil que el especialista en derecho conozca a fondo sus obras metafísicas y teológicas, o quien trabaje teología y filosofía de la religión acceda a sus tratados psicológicos, de tema político y jurídico, etc. Además, es un autor controvertido por la tensión — de la que es difícil hacerse cargo- entre continuidad con el pensamiento escolástico, tomista y escotista, y modernidad desde la que es leído, reactualizado y relacionado por la historiografía posterior.

Ya en vida de Suárez hay esa tensión entre "escuela" y "novedad”. Según señala su biografía más conocida ${ }^{5}$, durante su docencia las

3. Las actividades organizadas al efecto fueron: Workshop Internacional: Perspectivas del 'De legibus' de Francisco Suárez, Universidad de Navarra, Pamplona 20 de junio de 2014 (co-organizado por Mauricio Lecón y $M^{\text {a }}$ Idoya Zorroza); el Simposio de la Línea Especial de Pensamiento clásico español: El tratado 'De anima' de Francisco Suárez y su proyección en la filosofía moderna, Pamplona, 14-15 de mayo de 2015 (organizado por José Angel García Cuadrado); Workshop Internacional: La proyección de Francisco Suárez en la filosofía moderna, Pamplona, 24 de junio de 2016.

4. LIII Reuniones Filosóficas Francisco Suárez: Escolástica y Mundo Moderno, Pamplona, 26-28 de abril 2017 (co-organizadas por Agustín Echavarría, José Ángel García Cuadrado y $\mathrm{M}^{\mathrm{a}}$ Idoya Zorroza).

5. Era el segundo curso de Artes o Filosofía que impartía (en 1573) en el primer colegio al que fue enviado para desarrollar su docencia, en la ciudad de Segovia (15711574), señala su biógrafo R. de SCORRAILle, El P. Francisco Suárez de la Compañia de Jesús, según sus cartas, sus demás escritos inéditos y crecido número de documentos nuevos (E. Subirana, Barcelona, 1917), 134-138. O en sus primeras clases de Teología en Valladolid (1576-80) (cfr. Ibidem, 151-158), en sus escritos (Ibidem, 248-249), en un momento en que también era cuestionada la propia Compañía (Ibidem, 226-227), por ejemplo, con la polémica De auxiliis (1581-1608) (Ibidem, 329-448). 
acusaciones de profesar "teorías nuevas" fue constante, ya desde sus primeros años; también durante su actividad docente, tanto internamente dentro de la orden, como sobre sus escritos publicados, y también externamente, con la oposición de otros teólogos del momento. Por eso la discusión sobre cómo sus propuestas introducen continuidad al planteamiento filosófico y teológico escolástico en la búsqueda de la verdad, junto a la novedad en planteamientos que "sonaban" diferentes y sin suficiente probación, es una constante que acompañó a Francisco Suárez durante toda su carrera académica, y que persiste en la interpretación que se ha hecho de sus teorías y escritos.

Zubiri hacía valer este carácter bivalente: Por un lado, "la riqueza y precisión infinitesimal del vocabulario escolástico constituye uno de los tesoros que es más urgente poner en rápida circulación” y "las Disputationes de Suárez constituyen la enciclopedia del escolasticismo, [...] no ha dejado escapar Suárez ninguna idea u opinión

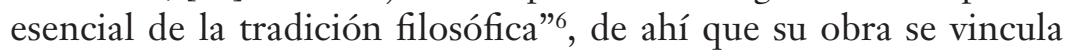
con la larga tradición escolástica, con la que es coherente en temas y tratamiento. Pero al mismo tiempo "la sistematización a que ha sometido estos problemas y su originalidad al repensarlos han traído como consecuencia que el pensamiento antiguo continúe en el seno de la naciente filosofía europea del siglo XVII y haya entregado a ella muchos de los conceptos sobre que se halla asentada" , por lo que en Suárez se encuentra de una manera muy clara esa función de eslabón o de gozne entre el pensamiento medieval y la modernidad. O como se ha llegado a señalar, Suárez es el conducto por el que la tradición escolástica llega a los que serán reconocidos como los primeros filósofos modernos ${ }^{8}$. Por ello, o es un autor considerado como referencia para superar y revertir la deriva de la metafísica occidental en su olvido del ser — al seguir una vía onto-teológica que llega hasta la filosofía alemana' — como en Heidegger, o signi-

6. X. ZubIRI, Suárez, en Naturaleza, historia, Dios (Alianza Editorial / Sociedad de Estudios y Publicaciones, Madrid, 1987) 161.

7. X. ZUBIRI, op. cit., 162.

8. A. Maurer, Medieval Philosophy (Random House, New York, 1967) 356.

9. M. Heidegger, El ser y el tiempo (Fondo de Cultura Económica, México, 1967) 32. 
fica un cambio de rumbo de la filosofía escolástica "culpable" de la deriva racionalista e idealista ${ }^{10}$, o la voz más preclara y culmen de la escolástica a la cual compendió, desde su posición privilegiada como uno de sus últimos autores, en cada uno de los temas que abordaba.

Por eso, la figura de Suárez es la de un pensador que trasciende definiciones, épocas y límites y cuyas obras siguen dando qué pensar, a pesar de los años transcurridos.

Y es que Francisco Suárez, como los autores de la Escolástica española de los siglos XV-XVII, tuvo ante sí un gran reto: dar razón de un mundo, ya radicalmente moderno, desde las estructuras intelectuales que hereda, tensando al máximo los problemas y los recursos conceptuales para comprenderse y comprender su tiempo y su mundo.

Por eso, para la investigación contemporánea, además del valor e interés intrínseco de su obra, Suárez es un autor de gran relevancia, por dos motivos: primero, porque como continuador del método y del proceder escolástico, en sus obras se compendian la tradición teológico-filosófica (desde las fuentes greco-latinas, los comentadores aristotélicos, los grandes autores medievales, especialmente el dominico Tomás de Aquino, cuya Summa comenta, además del franciscano Juan Duns Escoto), los Teólogos, comentadores de Santo Tomás o de las Sententiae de Pedro Lombardo que son coetáneos con su actividad, la gran tradición jurídica y canónica europea, y otros autores literarios, que reflejan la formación humanística que recibió como jesuita. Por eso sus escritos son como una gran enciclopedia del saber de su momento y de la tradición que le precedió. Además, porque no se contentó con hacer una historia de las ideas, sino que propuso un pensamiento en parte original que fue recibido y muy difundido por toda Europa y la floreciente América. Según ello, puede verse con claridad cómo hay una continuidad de ideas entre, por ejemplo, la metafísica de Francisco Suárez y la del racionalismo de Descartes y Leibniz; o de las ideas políticas suarecianas con las del pensamiento inglés de Locke, que se reconoce como origen de las tesis y las declaraciones de los derechos humanos

10. É. GILSON, El ser y los filósofos (Eunsa, Pamplona, 1985) 182. 
o derechos del hombre. Además del interés que puede despertar su pensamiento para otras disciplinas, como la epistemología, la filosofía del lenguaje, la filosofía y teoría de la acción, la ontología, la filosofía del derecho, etc.

Se le ha considerado el "eslabón" que vincula dos épocas y dos modos de hacer filosofía: por un lado, la filosofía escolástica, que se nutre de la tradición greco-latina, enriquecida por la reflexión patrística y las discusiones escolásticas de los siglos XII-XVI; por otro, la naciente filosofía moderna, que desde Descartes, Leibniz (representantes del racionalismo), Hobbes o Locke (representantes del empirismo) arranca en un discurso que configurará el mundo y las ideas contemporáneas. Y tanto si se interpreta que es un "eslabón" que conecta continuando, como si se le presenta como cierre y comienzo de otra realidad intelectual, Francisco Suárez es un autor que merece el estudio detenido de su obra, pues, a pesar de los muchos estudios ya realizados sobre Suárez, este autor sigue siendo una figura por descubrir.

Como se decía al principio, este cuarto centenario de su fallecimiento es la ocasión de reactualizar a uno de los grandes intelectuales del pensamiento español, y de dialogar con sus propuestas fundamentales para incorporar sus reflexiones y sus propuestas a la labor siempre vigente de comprender al hombre, su mundo y su tiempo. Con esta intención se ha proyectado este volumen monográfico de Anuario Filosófico, un volumen que no ha querido centrarse en una dimensión de la obra de Francisco Suárez de manera excluyente sino, al contrario, intentar ofrecer un modesto panorama de su actualidad en distintas disciplinas.

Por ello, en el índice del volumen se pueden apreciar los múltiples intereses que despierta este jesuita granadino: desde la filosofía del derecho y teoría económica (en el trabajo de Fernando Hernández Fradejas, "Derecho de propiedad privada y fiscalidad en Francisco Suárez”), pasando por la relación de Suárez con Hobbes en filosofía política (en el escrito de Miguel Saralegui, "La conciliación de lo político y lo religioso. Suárez y Hobbes sobre la potestad indirecta"), la psicología filosófica (con el texto de Daniel Heider, "Suárez on sound and hearing"), la metafísica (en el estudio de Mau- 
ricio Lecón, "Recuperación suareciana de los conceptos aristotélicos

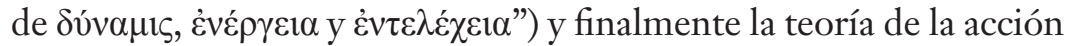
(con el artículo de David González Ginocchio, "Praxis and the ends of action in Suárez").

El monográfico arranca con el artículo "Derecho de propiedad privada y fiscalidad en Francisco Suárez" del Dr. Fernando Hernández Fradejas (Facultad de Derecho, Universidad de Valladolid), especialista en teoría económica de la Escuela de Salamanca, analiza la noción de derecho de propiedad privada en Francisco Suárez y el tratamiento de la propiedad en materia fiscal, queriendo abordar una de las cuestiones menos conocidas del pensamiento suareciano y que este autor abordó de manera central en su De legibus.

El artículo del Dr. Miguel Saralegui (Instituto de Humanidades, Universidad Diego Portales, Chile) de título "La conciliación de lo político y lo religioso. Suárez y Hobbes sobre la potestad indirecta", compara las tesis de filosofía política de Hobbes en lo relativo a la convivencia o subordinación entre dos formas de poderes: el poder político y el poder religioso. Apostando ambos autores por la conciliación de ambos poderes como realmente diferentes entre sí, pese al distinto punto de partida que se encuentra en ambos autores, la paz sólo surge por la subordinación de uno a otro, sea por un criterio religioso, sea por uno político.

El Dr. Daniel Heider (Faculty of Theology, University of South Bohemia), coordinador del Proyecto de investigación sobre Filosofía escolástica barroca en Chequia, estudia en su artículo "Suárez on sound and hearing" el sentido externo "delegado" a la posición de "segundo sentido" en una posición visiocéntrica como la medieval. Sin embargo, el análisis del objeto, el órgano y la realidad del oír, produce una interesante confrontación entre la noción de autoridad como paradigma y el valor, cada vez más creciente, de la experiencia, tensión que se encuentra en la obra de Suárez y que es ejemplificada al realizar una teoría de la percepción sobre dicho sentido.

El artículo del Dr. Mauricio Lecón (Universidad Panameri-

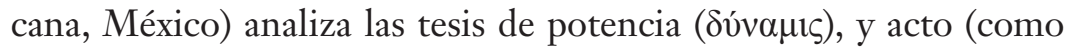

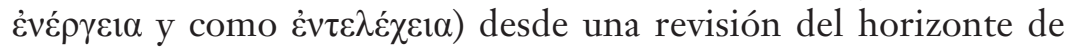
comprensión suareciano, considerándolo no tanto un renovador 
como un comentador de Aristóteles; desde esta vía de acceso a la metafísica suareciana el autor pondrá entre paréntesis la supuesta reducción de la potencia al acto en Suárez, subrayando su contenido aristotélico fundamental.

Finalmente, el artículo del Dr. David González Ginocchio (Universidad Internacional de La Rioja), "Praxis and the ends of action in Suárez", aborda un nudo de la teoría de la acción como es la coordinación de intelecto y voluntad, vinculando a Suárez con la tradición que le antecede, en particular con las tesis de Juan Duns Escoto y Tomás de Aquino, a los que la historiografía ha presentado como dos modelos enfrentados e irreconciliables. Su propuesta principal es la presentación del fin como bien, elemento necesario para una consideración subjetiva de lo operable.

Si la historia de la filosofía "hace de Suárez un factor imprescindible para la intelección de la filosofía moderna"11, con este monográfico hemos querido mostrar la necesidad de realizar un diálogo intelectual con él también para la tarea que compete al intelectual de hoy de pensar y abordar los nudos de nuestra realidad.

Queremos transmitir nuestro agradecimiento tanto a los colaboradores de este volumen, por sus trabajos y su saber hacer, como a los investigadores de la Línea Especial que en las sesiones de organización y planificación de las actividades de este cuarto centenario de la muerte de Francisco Suárez fueron ayudando a la ahora realidad de este monográfico de Anuario Filosófico. Y, especialmente, el reconocimiento a la persona que lo animó y lo preparó hasta su fallecimiento, el Prof. Dr. Ángel Luis González, cuya huella sentimos tan cerca y presente todavía.

11. X. Zubiri, op. cit., 162. 
ESTUDIOS 
